\title{
A DECISION SUPPORT SYSTEM FOR A CRANE PLAN AS PART OF A GENERIC CONSTRUCTION PLAN
}

\author{
Frans van Gassel and Wim Schaefer \\ Eindhoven University of Technology, Faculty of Architecture, \\ Building and Planning \\ Department of Construction Engineering and Management, \\ Eindhoven, The Netherlands. \\ f.j.m.v.gassel@bwk.tue.nl andw.f.schaefer@bwk.tue.nl
}

\begin{abstract}
After a building has been designed the construction process necessary to make the building also has to be designed. The theoretical framework of the "Construction Plan" has been adapted to our research project in order to structure the design of this process. The crane plan exists in this framework as an important sub-plan. A crane is a very important piece of equipment on the construction site. It can influence production time, costs, working conditions and the quality of the product. The choice of a suitable crane is essential in designing the construction process. We have developed a crane plan as a decision support tool that fits into the generic framework of the Construction Plan, using a knowledge base and a database for cranes. This not only supports the choice of a crane necessary for the job, but also takes account of relationships between construction subplans and specific scenarios within the whole context of the construction process. The crane plan has been tested by making use of an expert panel and by applying for the reconstruction of a recently finished construction process.
\end{abstract}

Keywords: Crane Plan, Construction Plan, Decision Support Systems.

\section{INTRODUCTION}

Construction activities complete the building to the extent that the requirements of the contract documents are met as well as the needs, expectations, and conditions of the party that commissioned the building and its potential users. Before those activities can start on site, a rather complex production process of on-site activities has to be developed and a generic plan for the construction designed.

This paper describes a tool for designing one part of this generic plan. Developing tools for designing production processes for buildings on site is one of the research topics of the Construction Engineering and Management Department at Eindhoven University of Technology. This research group has developed a theoretical framework for an integrated approach to the aforementioned generic construction plan. Within the boundaries of this theoretical framework, a decision support tool for designing the crane plan has been developed [8]. Use of this crane planner is limited to the construction processes for (non-) residential buildings, where telescopic, crawler and tower cranes are used. We describe the incorporation of the crane planner into the "Construction Plan". A prototype of this decision support tool has been built as a software package.
The model of the crane planner is explained as well as the validation results.

\section{CONSTRUCTION PLAN}

In the building trade, there is a growing realisation that the work preparation phase is crucial to the building process. To achieve maximum output in the construction process, an integrated plan for that process has to be designed: the Construction Plan (see figure 1). The process designer creates the best possible construction plan with the help of Decision Support Systems. A specific theoretical framework for that plan is a platform for the approach we have chosen to developing a decision support tool for the use of cranes in the construction process.

A database where all information can be stored is a major part of the process of designing the Construction Plan. Information can be external (architect or supplier) or internal (the tentative results of the Construction Plan).

This theoretical framework consists of a number of related plans and scenarios (see figure 2). Leijten et al. distinguished a collection of plans and scenarios in the Construction Plan. A plan contains data on a specific production aspect like setting up, safety or equipment needs. All data on the production of a 
single part of the project or a building element are included in a scenario.

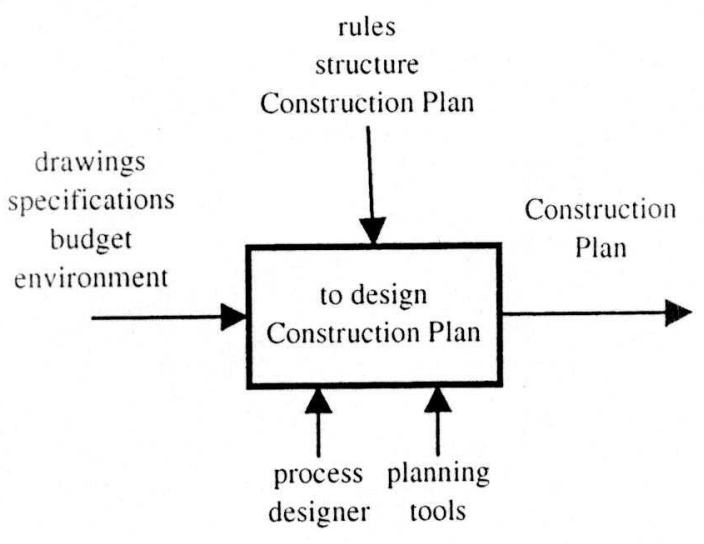

Figure 1. Input and output designing process
of Construction Plan.

The plans and scenarios are represented in a diagram: the plans are shown horizontally and the scenarios vertically. The information for the plans and scenarios comes from a single database.

\section{THE CONSTRUCTION PLAN}

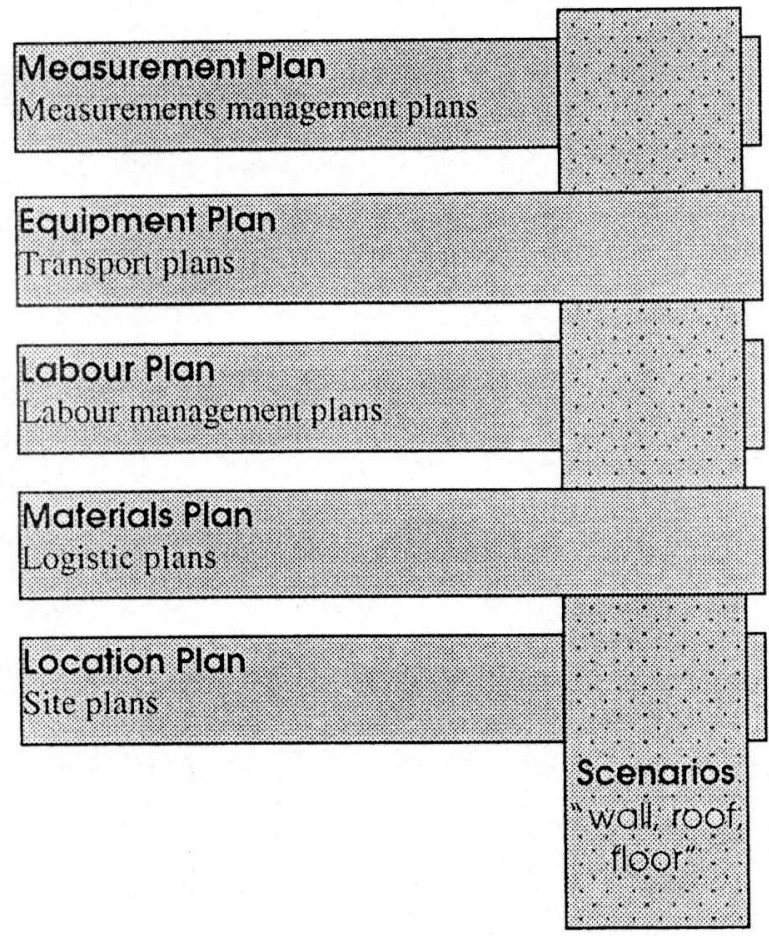

Figure 2. Schematic Layout for the

"Construction Plan". The "sub-plans" are listed horizontally. The scenarios for producing building parts, which are interrelated with the "sub-plans", are listed vertically. (6)

\section{TRANSPORT AND CRANE PLANS}

The Transport Plan is a specific part of the Construction Plan. This can be described as follows:

"A transport plan is a set of documents that describe how, during the production phase of a building. the material and equipment transport is organised to. on and from the construction site." [2]

The Transport Plan consists of the following documents:

1. Transport specifications of materials and equipment.

2. Transport equipment specifications.

3. Transport equipment planning.

4. Layout of construction site.

The Crane Plan is a sub-plan of the Transport Plan. Examples of other sub-plans would be a concrete transport plan or a plan to transport workers.

In the literature, we found different kinds of tools to design a crane plan. First, there are the crane manufacturers, such as Liebherr or Potain, who have made software programs for choosing crane types. The properties of the crane chosen and the situation at the construction site can be reviewed on a laptop screen.

The Technical University of Munich designed a tower crane-planning tool. Inputs are the load, radius and hoist height. The output of the planner is the crane type [10].

On the Internet site www.liftplanner.com, there is a planning application by A.P.M.S. QId Pty Ltd with the same properties as the Munich application.

Gray and Little [4] designed an expert system for the selection of an appropriate mobile or tower crane for a construction site. The system contains tips for the crane planner for making decisions. The output is the crane profile. A cost calculation is not provided.

Van Dijk [1] developed an expert system that comes up with a crane profile. This system can be integrated on the Internet and is used to generate a flow chart.

Williams and Bennett [9] designed an Automated Lift Planning System (ALPS). It is a graphical crane and rigging simulation tool for simulating heavy lifts and preparing lift plans. ALPS allows users to graphically simulate the entire lift sequence, animate the process, and play back the lift either online or on video in order to communicate the lift plan to others. The software is available.

Ito and Kano [5] designed a 3-D graphical simulation for crane planning using an object-oriented building product model that supports simulation, visualisation and documentation of crane planning with userfriendly interfaces. The most important point in 
developing this system is that it proved the concept of the new type of 3-D graphical simulation with evaluations of cost, scheduling and other planning factors.

In the ISARC 15 paper, Van Gassel [3] distinguished three levels of crane planners: long-term, one-day and online planning tools. He reaches the conclusion that these planners must be integrated.

At the University of Texas, some studies on lift planning have been carried out. See Internet site www.ce.utexas.edu/prof/haas. The subject of these studies is heavy lifts.

\section{CRANE PLAN WITHIN THE CONTEXT OF THE TRANSPORT PLAN}

As explained in the introductory sections 1 and 2, the approach for developing the Construction Plan is based on the idea of a set of well-described and "interrelated" (interactive) plans and scenarios. In terms of the system theory, the Transport Plan is a system, the boundaries of which consist of the Construction Plan system. The Crane Plan can be interpreted as a system within the boundaries of the Transport Plan system. In figure 3, the relationship between systems and sub-systems is represented with the notation "Structured Analysis and Design Technique" [7].

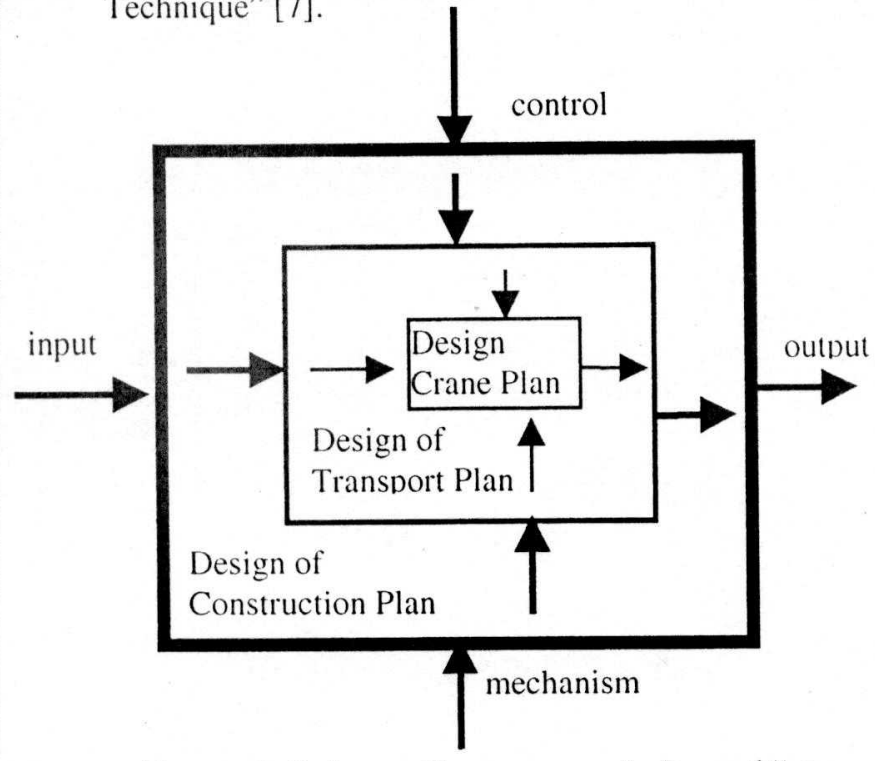

Figure 3. Schematic representation of the Crane Plan as a system within the Transport Plan, which is a system within the boundaries of the Construction Plan.

After analysing available developments for crane plans and considering experiences with the aforementioned crane planners in section 3, a "new" crane planner has been developed that fits within the context of the Transport Plan, as a part of the Construction Plan.
This Crane Plan is described as follow [8]:

"A crane plan tells about costs, cranes, where and when to transport particular building parts from where to where."

More specifically, the Crane Plan is defined by its output, which is stated as:

- the position of the crane on the construction site,

- the specification of the crane,

- the planning of the hoist activities,

- the costs of the crane plan,

- building parts to transport by crane,

- pick up and deposit sites for building parts.

Some other outputs can be used as input for the database. See figure 4.

drawings

specifications

environment

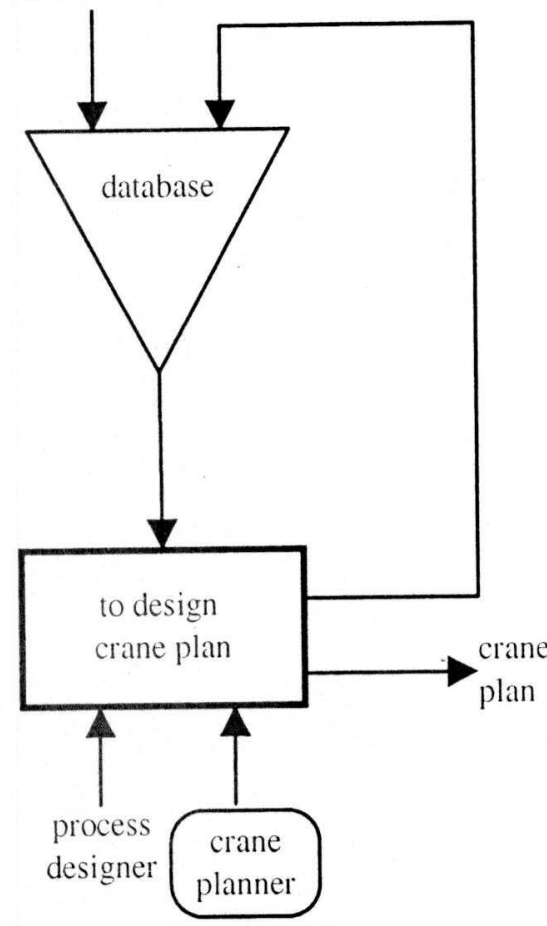

Figure 4. The design process of a crane

plan.

The database consists of the following information items:

- Environment: condition of the soil, surrounding buildings, building site, etc.

- Building: building materials and parts, details, building methods, etc.

- Project: contracts, prices, laws, etc.

- Cranes: types, specifications, costs, hoist equipment, etc.

- Knowledge: rules, tips, etc.

Some of this information is incorporated in the plans and scenarios of the (tentative) construction plan. 


\section{THE MODEL OF THE CRANE PLAN}

The four elements of the model of the Crane Plan are:

1. Knowledge base.

2. Procedures base.

3. Data processing.

4. User interfaces.

\section{I Knowledge base}

The model can store knowledge in the database of the construction plan. The knowledge has been gathered from the literature and from interviews with experts in the construction industry. With this knowledge, the crane planner can make decisions according to the rules in the system. The process designer can also make decisions based on knowledge in the system or his own knowledge.

Some examples of these rules are:

- For three-month use of a crane, a tower crane is indicated.

- The distance between two tower cranes is five metres.

- Minimal distance between crane and surroundings.

- Minimal distance between the jib of two tower cranes.

\subsection{Procedures base}

The model contains the following main procedures:

1. To determine crane effort.

2. To determine crane type.

3. To determine crane position.

4. To specify crane.

5. To determine crane costs.

6. To set up crane plan.

Each main procedure consists of four to six subprocedures.

These procedures use a database with information about: crane properties, subscriptions about crane use, safety laws, etc.

\subsection{Data processing}

The crane planner is developed by making use of the Delphi 3.0 programming environment. The application runs on a standard Windows 95 computer. This paper does not give a description of this development. The whole program consists of 90 screens for the user interface.

\subsection{User interface}

The main menu of the crane planner comprises the same six steps as described in section 5.2

The structure of the screens is:

- one part for the menu and a tree view (where the designer is in the design process),

- one part for the input of information and

- one part for showing the tentative results of the crane plan.

Examples of screens with tentative planning results are:

- A 3-D drawing of the building. The building parts which had to be transported by crane are highlighted

- Long-term planning of the building process.

- A diagram on which the weight is indicated on the vertical axis and the radius of the crane on the horizontal axis.

- A crane scheme for a particular crane. In this scheme the crane planner can match the crane demand with several crane types.

- A 3-D drawing of the building with the chosen crane.

- An overview of the costs of the crane plan: transportation of the crane, foundation, assembling, hiring and operation.

\section{RESULTS}

In co-operation with Schepers and Woudenberg. we built a prototype of the crane planner and tested it on a building project. A Crane Plan was designed for the transport of prefabricated concrete columns and walls and for floor elements, reinforcement and concrete. In total, 7,070 building parts for five floors. Two methods were used to validate research output. One method was to use an expert panel for judging the output of "our" Crane Plan for a hypothetical project. The second method was to put all the data and rules for a recently finished construction project into the databases of the Crane Plan and see if the suggestions made by our program for choosing the cranes were similar to those that had been made in the real world of the finished project.

The strong points are:

- Automatic calculation of the degree of capacity utilisation and drawing of crane diagrams by the computer. It would take too much time to do this by hand.

- It is now possible to design and evaluate two crane plans.

- In the Crane Plan, the process designer can make his own decisions and the system helps him with time-consuming work. 
- Giving the process designer tips and rules is very useful. In this way, knowledge becomes available to more people.

The weak points are:

- Not all the information needed to work with the planner is available to the construction firm. The drawings for the building must be supplied in CAD files.

- When the designer wants to change something he has to go through the whole program.

- What will the economic benefits of this rather expensive DDS tool be?

\section{DISCUSSION}

The Crane Plan was developed within the rigid context of a theoretical framework for designing construction processes. This framework has been addressed in sections 2 and 4 . The whole of the research effort demonstrated the idea that a set of interrelated design decision tools has to be available for designing construction processes. On the other hand, the stand-alone performance of the Crane Plan was interesting. The real-world experts were satisfied by the program's output.

From this perspective, one major step forward in modelling our framework for the Construction Plan has been accomplished. Other sub-plans must be developed, also taking into account the function and reliability of the sub-plan itself and the way such a tool is interrelated with the other decision support tools in the "Construction Plan".

The next steps in developing this tool for crane planning are:

- To complete the software programs: connecting the object-oriented drawing and planning software.

- To gather more knowledge.

- To integrate the crane planner with the other tools used for designing the construction plan.

\section{ACKNOWLEDGEMENTS}

We thank Rob van Zutphen of the Design Systems Department of our faculty for his support in programming the crane planner.

\section{REFERENCES}

[1] M. van Dijk, 1997. Tower Crane Choice on the Internet, Eindhoven University of Technology (in Dutch)

[2] F. van Gassel, 1994, Transport plan, Lecture notes Construction Engineering and Management, Eindhoven University of Technology (in Dutch).

[3] F. van Gassel, 1998, Electronic Planning Tools for Tower Cranes, Proceedings of the International Symposium for Automation and Robotics in Construction, ISARC 15, Munich.

[4] C. Gray and J. Little, A Systematic Approach to the selection of an appropriate crane for a construction site, Construction Management and Economics, 1985, no. 3, p 121-144.

[5] K. Ito and Y. Kano, 1997, 3-D Graphical Simulation for Crane Planning using ObjectOriented Building Product Model. CIB proceedings Information Technology Support for Construction Process Re-engineering, Cairns, Queensland, Australia.

[6] Leijten, E., G. Maas, E. Vastert, 1997. Knowledge aspects of construction planning redesign. In Drogemuller, R. (Ed): CIB W78Information Technology in Construction, proceeding CIB/James Cook University, Cairns.

[7] Marca, David A, and Clement L. McGowan, 1988, SADT: structured analyses and design technique, McGraw - Hill.

[8] C. Schepers and W. van Woudenberg, 1998. A Decision Support System for the design process for a crane plan. Graduation thesis Eindhoven University of Technology (in Dutch).

[9] M. Williams and C. Bennett, 1996, ALPS: The Automated Lift Planning System, ASCE Third Congress on Computing in Civil Engineering. Anaheim, CA.

[10] Munich, BKT Turmdrehkran-Einzatzplaner. Leaflet Munich University of Technology 